\title{
Mouse models characterize GNAO1 encephalopathy as a neurodevelopmental disorder leading to motor anomalies: from a severe G203R to a milder C215Y mutation
}

Denis Silachev ${ }^{1,2,3,4}$, Alexey Koval ${ }^{3}$, Mikhail Savitsky ${ }^{3}$, Guru Padmasola ${ }^{5}$, Charles Quairiaux ${ }^{5}$, Fabrizio Thorel ${ }^{6}$ and Vladimir L. Katanaev $3,4^{*}$ (1)

\begin{abstract}
GNAO1 encephalopathy characterized by a wide spectrum of neurological deficiencies in pediatric patients originates from de novo heterozygous mutations in the gene encoding Gao, the major neuronal G protein. Efficient treatments and even the proper understanding of the underlying etiology are currently lacking for this dominant disease. Adequate animal models of GNAO1 encephalopathy are urgently needed. Here we describe establishment and characterization of mouse models of the disease based on two point mutations in GNAO1 with different clinical manifestations. One of them is G203R leading to the early-onset epileptic seizures, motor dysfunction, developmental delay and intellectual disability. The other is C215Y producing much milder clinical outcomes, mostly-late-onset hyperkinetic movement disorder. The resultant mouse models show distinct phenotypes: severe neonatal lethality in GNAO1[G203R]/+ mice vs. normal vitality in GNAO1[C215Y]/+. The latter model further revealed strong hyperactivity and hyperlocomotion in a panel of behavioral assays, without signs of epilepsy, recapitulating the patients' manifestations. Importantly, despite these differences the two models similarly revealed prenatal brain developmental anomalies, such as enlarged lateral ventricles and decreased numbers of neuronal precursor cells in the cortex. Thus, our work unveils GNAO1 encephalopathy as to a large extent neurodevelopmental malady. We expect that this understanding and the tools we established will be instrumental for future therapeutic developments.
\end{abstract}

Keywords: GNAO1, Gao, Encephalopathy, Mouse model, Dominant, Epilepsy, Hyperkinetic movement disorder, Neurodevelopmental, Neuronal precursors

\footnotetext{
*Correspondence: vladimir.katanaev@unige.ch

${ }^{3}$ Department of Cell Physiology and Metabolism, Faculty of Medicine,

Translational Research Center in Oncohaematology, University of Geneva,

1211 Geneva, Switzerland

Full list of author information is available at the end of the article
}

\section{Introduction}

GNAO1 encephalopathy is a group of neurological disorders, manifesting in infants and children and caused by heterozygous and mainly de novo mutations in GNAO1the gene encoding the major neuronal G protein Goo [14]. One of the hotspots of mutations, c.607G > A producing the Goo[G203R] protein variant, leads to the most severe manifestations of the disease: early onset (sometimes days after birth) epileptic seizures, severe motor dysfunctions, original author(s) and the source, provide a link to the Creative Commons licence, and indicate if changes were made. The images or other third party material in this article are included in the article's Creative Commons licence, unless indicated otherwise in a credit line to the material. If material is not included in the article's Creative Commons licence and your intended use is not permitted by statutory regulation or exceeds the permitted use, you will need to obtain permission directly from the copyright holder. To view a copy of this licence, visit http://creativecommons.org/licenses/by/4.0/. The Creative Commons Public Domain Dedication waiver (http://creativeco mmons.org/publicdomain/zero/1.0/) applies to the data made available in this article, unless otherwise stated in a credit line to the data. 
developmental and intellectual delay, and brain malformations (Table 1). This mutation has been clinically described in 7 patients [1, 2, 5-7] (Table 1); a recent survey reported 12 patients with the Goo[G203R] substitution [3].

On the other extreme of the reported GNAO1 mutations, c.644G > A resulting in the $\mathrm{G \alpha o}[\mathrm{C} 215 \mathrm{Y}]$ protein variant has a relatively late age of onset (3 to 12 years), no signs of epilepsy, mild or no intellectual disability. Clinically, the $\mathrm{C} 215 \mathrm{Y}$ mutation manifests as various types of motor dysfunction, manly myoclonus dystonia, which, however, permit the patients to work and have families $[8,9]$ (Table 1).

No curative but only symptomatic treatments with mixed, mostly mild and temporary, treatment outcomes have so far been available to GNAO1 patients $[3,10,11]$. Development of curative therapies has as prerequisites the understanding of the molecular etiology of the disease, as well as the establishment of proper animal models. We thus set to model these two GNAO1 mutations-the severe G203R and the mild C215Y-in the mouse. Our results reveal the early postnatal lethality of GNAO1[G203R]/+ but not GNAO1[C215Y]/+ mice, varying brain developmental malformations in both genotypes, and hyperlocomotion behavior of the C215Y/+ mutant mice. This latter phenotype can be viewed as the mouse analog of the hyperkinetic movement disorder of the human $\mathrm{C} 215 \mathrm{Y}$ patients $[8,9]$. Our work thus describes important rodent models of GNAO1 encephalopathy and further highlights it as to a large extent neurodevelopmental disease. These models will be instrumental in the drug discovery/development targeting GNAO1 encephalopathies.

Table 1 C215Y and G203R patients described in the literature. Patient 2 is the mother of patient 3. All other cases are de novo mutations

\begin{tabular}{|c|c|c|c|c|c|c|c|c|c|}
\hline Pat.\# & Sex & $\begin{array}{l}\text { Nucleotide } \\
\text { change }\end{array}$ & $\begin{array}{l}\text { Amino } \\
\text { acid } \\
\text { change }\end{array}$ & $\begin{array}{l}\text { Age of onset } \\
\text { (age at } \\
\text { publication) }\end{array}$ & Epilepsy & $\begin{array}{l}\text { Movement } \\
\text { disorder }\end{array}$ & $\begin{array}{l}\text { Intellectual } \\
\text { disability / } \\
\text { developmental } \\
\text { delay }\end{array}$ & $\begin{array}{l}\text { Brain alterations } \\
\text { (MRI) }\end{array}$ & Reference \\
\hline 1 & M & c. $644 \mathrm{G}>\mathrm{A}$ & C215Y & $12 y(42 y)$ & No & $\begin{array}{l}\text { Myoclonus dys- } \\
\text { tonia }\end{array}$ & No & No & [9] \\
\hline 2 & $\mathrm{~F}$ & c. $644 \mathrm{G}>\mathrm{A}$ & C215Y & $5 y(66 y)$ & No & $\begin{array}{l}\text { Non-progressive } \\
\text { generalized } \\
\text { dystonia, myo- } \\
\text { clonus, pyramidal } \\
\text { syndrome }\end{array}$ & No & NA & [8] \\
\hline 3 & M & c. $644 \mathrm{G}>\mathrm{A}$ & C215Y & $3 y(31 y)$ & No & $\begin{array}{l}\text { Non-progressive } \\
\text { generalized dysto- } \\
\text { nia, myoclonus }\end{array}$ & $\begin{array}{l}\text { Mild intellectual } \\
\text { disability }\end{array}$ & No & [8] \\
\hline 4 & $\mathrm{~F}$ & c. $607 \mathrm{G}>\mathrm{A}$ & G203R & 7 m (8y) & Yes & $\begin{array}{l}\text { Severe chorea, } \\
\text { athetosis }\end{array}$ & $\begin{array}{l}\text { Developmental } \\
\text { delay }\end{array}$ & $\begin{array}{l}\text { Delayed myelina- } \\
\text { tion, thin corpus } \\
\text { calossum }\end{array}$ & [2] \\
\hline 5 & $\mathrm{~F}$ & c. $607 \mathrm{G}>\mathrm{A}$ & G203R & $7 d(14 m)$ & Yes & Severe chorea & $\begin{array}{l}\text { Developmental } \\
\text { delay }\end{array}$ & $\begin{array}{l}\text { Cerebral atrophy, } \\
\text { delayed myelina- } \\
\text { tion }\end{array}$ & {$[5]$} \\
\hline 6 & M & $c .607 \mathrm{G}>\mathrm{A}$ & G203R & 1 m (5y) & yes & $\begin{array}{l}\text { Severe chorea, } \\
\text { athetosis }\end{array}$ & $\begin{array}{l}\text { Developmental } \\
\text { delay }\end{array}$ & $\begin{array}{l}\text { Progressive } \\
\text { atrophy }\end{array}$ & {$[6]$} \\
\hline 7 & $\mathrm{~F}$ & $c .607 \mathrm{G}>\mathrm{A}$ & G203R & 3 m (6y) & Yes & $\begin{array}{l}\text { Dyskinesia, dys- } \\
\text { tonia }\end{array}$ & $\begin{array}{l}\text { Motor develop- } \\
\text { mental delay, intel- } \\
\text { lectual disability }\end{array}$ & $\begin{array}{l}\text { Progressive atro- } \\
\text { phy, thin corpus } \\
\text { calossum }\end{array}$ & [7] \\
\hline 8 & $\mathrm{~F}$ & c. $607 \mathrm{G}>\mathrm{A}$ & G203R & $9 d(4 y)$ & Yes & $\begin{array}{l}\text { Dyskinesia, dys- } \\
\text { tonia }\end{array}$ & $\begin{array}{l}\text { Motor develop- } \\
\text { mental delay, intel- } \\
\text { lectual disability }\end{array}$ & Mild atrophy & [7] \\
\hline 9 & $\mathrm{~F}$ & c. $607 \mathrm{G}>\mathrm{A}$ & G203R & $1 d(3 y)$ & Yes & $\begin{array}{l}\text { Generalized hypo- } \\
\text { tonia, mild dyski- } \\
\text { nesia, generalized } \\
\text { dystonia, chorea }\end{array}$ & $\begin{array}{l}\text { Severe neurode- } \\
\text { velopmental delay }\end{array}$ & $\begin{array}{l}\text { Thin corpus calos- } \\
\text { sum }\end{array}$ & [1] \\
\hline 10 & M & c. $607 \mathrm{G}>\mathrm{A}$ & G203R & $12 d(5 y)$ & Yes & $\begin{array}{l}\text { Hypotonia, dyski- } \\
\text { nesia, hyperkinesia, } \\
\text { status dystonicus, } \\
\text { dystonia }\end{array}$ & $\begin{array}{l}\text { Developmental } \\
\text { delay }\end{array}$ & $\begin{array}{l}\text { Hypomyelination, } \\
\text { brain atrophy }\end{array}$ & [1] \\
\hline
\end{tabular}




\section{Materials and methods}

\section{Animal experimentation}

All experiments involving animals were conducted in accordance with the Swiss law and authorized by the Swiss Federal Food Safety and Veterinary Office (authorizations \#GE/17/20 and \#GE/25/20).

\section{CRISPR/Cas9 mutagenesis}

To generate GNAO1[G203R] (c.607G $>\mathrm{A})$ and GNAO1[C215Y] (c.644G >A) mutant mice, we reconstituted CRISPR ribonucleoprotein complexes (RNP) containing the Cas9 protein with following gRNAs: gRNA_G203R: 5'-TGC AGGCTGTTTGACGTCGG-3'; gRNA_C215Y: 5'-CCG TGACATCCTCAAAGCAG-3'. As donor template, we used the following ssDNAs: ssDNA(G203R): 5'-ATGGCC GTGACATCCTCAAAGCAGTGGATCCACTTCTTG CGTTCAGATCGCTGGCCgCgGACGTCAAACAG CCT GCAGGGAGTCAGGGAAAGCTGT-3'; ssDNA(C215Y): 5'-GGCCAGCGATCTGAACGCAAGAAG TGGATC CACTaCTTTGAGGATGTCACGGCCATCATCTTCTG TGTCGCAC TCAGCGGCTATGACCAGG-3'. Cas9, gRNA and ssDNA were from Integrate DNA Technologies (Zurich, Switzerland). RNP complexes were co-injected with the appropriate donor ssDNA in C57BL/6 J one cell embryos before transfer into $\mathrm{CD} 1$ foster mothers. In attempts to establish the GNAO1[G203R] line, we performed three independent injection sessions resulting in a total of 377 transferred embryos. In total, 57 F0 pups were found in the cages after birth, either as living or dead animals, among which majority had G203R/+, G203R/G203R, or G203R/[frame shift truncation] genotypes. In total, nine F0 G203R/+ were born, of which seven were found still alive the night after birth, but five of them perished. G203R E18.5 embryos for the histological analysis were obtained through a transgenesis procedure described above, but followed by caesarian section and transcardial fixation of the embryos. The lethality associated with the G203R mutation cannot be due to off-target effects for the following two reasons. First, considering that the off-target events are sporadic [12] and assuming their 50\% frequency [13] we arrive at the zero probability of a reiterating secondary lethal mutation to be observed in the $16 \mathrm{G} 203 R /+$ or $G 203 R / G 203 R$ pups. Second, excluding a non-sporadic off-target mutations, the fact that only G203R/+ and G203R/G203R F0 pups were neonatal lethal, as opposed to their littermates either wt/wt or containing a wt and a truncated allele of GNAO1, argues for the specific lethality caused by the G203R mutation, rather than potential off-target effects of gRNAs.

To generate the $C 215 Y$ line, 113 injected embryos were transferred in 1 session that resulted in the total of $30 \mathrm{F0}$ pups, among which we obtained one $C 215 Y /+$ and six C215Y/C215Y animals.

\section{Mouse genotyping}

Genomic DNA was isolated from fingers, pieces of tails, ears or legs of mice of different genotypes as described previously [14]. Induced point mutations and indels were verified by sequencing of PCR fragments obtained with the primers Fwd1_mGNAO1 (GACAGGTGTCACAGG GGATG) and Rev2_mGNAO1 (GGGCAGACAAGT GAACAAGTGAA). Sequencing was performed with the primers Rev1_mGNAO1 (TCCTAGCCAAGACCCCAA CT) or Fwd2_mGNAO1 (TCATCTGTCAGCCTGTTC CTCAC). All PCRs were performed using Phusion HighFidelity DNA Polymerase (New England Biolabs, Ipswich MA, USA) following the manufacturer's instructions.

Total RNA was isolated with the NucleoSpin RNA kit (Macherey-Nagel, Dueren, Germany) from pieces of brains or pieces of bodies. cDNA was synthesized by priming with oligo-dT with RevertAid Reverse Transcriptase (Thermo Fisher Scientific, Waltham MA, USA, cat. \#EP0441) following the manufacturer's instructions.

$160 \mathrm{bp}$ fragments partially overlapping 5th and 6th exons of GNAO1 were amplified from cDNA with primers mGNAO1_comfw (ACATCCTCCGAACCAGAG TCA) and mGNAO1_comrev (GTGCGACACAGAAGA TGATGG) and then sequenced.

\section{Fixation by transcardial perfusion}

The animals were anaesthetized by isoflurane induction dose $(5 \%)$ for $5 \mathrm{~min}$ followed by a maintenance dose of $2 \%$. The C-section was performed on pregnant mice, the pups were taken, analgezied (carprofen IP, 80-100 $\mu \mathrm{l}$ of $0.5 \mathrm{mg} / \mathrm{ml}$ solution, $5 \mathrm{mg} / \mathrm{kg}$ ) and immediately anesthetized by $5 \mathrm{~min}$ isoflurane induction dose (3\%) in the chamber. Afterwards, they were maintained at $2 \%$. After at least $10 \mathrm{~min}$ since carprofen injection, the pups were removed from chamber one by one, placed under the individual isoflurane mask and had an intracardiac perfusion of 1xPBS followed by fixation of the tissue with $4 \%$ paraformaldehyde in 1xPBS.

\section{Histological analysis and immunohistochemistry}

Brains from fixed E18.5 embryos were collected, fixed in $4 \%$ PFA, paraffin embedded and cut into $5 \mu \mathrm{m}$ thick sections. The sections were mounted on glass slides and stored at $4{ }^{\circ} \mathrm{C}$. Sections were deparaffinized, rehydrated and stained by hematoxylin-eosin or cresyl violet. For immunohistochemistry, sagittal sections were prepared from $+/+(\mathrm{n}=4), \quad \mathrm{C} 215 \mathrm{Y} /+(\mathrm{n}=4), \quad \mathrm{C} 215 \mathrm{Y} / \mathrm{C} 215 \mathrm{Y}$ $(\mathrm{n}=5), \quad \mathrm{G} 203 \mathrm{R} /+(\mathrm{n}=1)$ and G203R/G203R $(\mathrm{n}=2)$ samples. For the staining, the slides were first deparaffinized in three changes each of xylene, sequence of water mixtures of $\mathrm{EtOH}$ with decreasing concentrations (95\%, 
$70 \%$ and $50 \%)$ and finally water. Subsequently, antigen retrieval was performed in $20 \mathrm{mM}$ Tris-EDTA, pH 9.0 with $0.1 \%$ Tween- 20 by heating up the slides to $95^{\circ} \mathrm{C}$ for $20 \mathrm{~min}$ and gradual cooling to the room temperature. Further, the slides were blocked in $1 \mathrm{xPBS} / 0.1 \%$ Triton $\mathrm{X}-100$ with $1 \%$ of normal horse serum for $30 \mathrm{~min}$ at room temperature. They were then incubated with the different primary antibodies: Tbr1 (1:100, Abcam \#ab31940); Ctip2 (1:500, Abcam \#ab18465); Brn2 (1:200, Santa Cruz Biotechnologies \#sc-393324); Tbr2 (1:100, Abcam \#ab23345), Reelin (1:1000, Abcam \# ab230820), Nestin (1:200, Abcam \# ab6142), Cleaved Caspase-3 (1:200, Cell signaling \#9661). Secondary antibodies were conjugates of Alexa Fluor 488, Alexa Fluor 594, and Alexa Fluor 647 (1:250). DAPI (4,6'-diamidino-2-phenylindole) was used as nuclear counterstaining at $1 \mu \mathrm{g} / \mathrm{ml}$. Finally, slices were washed and mounted in Fluorescent Mounting Medium (Dako Cytomation). Genotype for samples was checked at the end of the experimental process. Cell counting was performed on rostral cortical regions (at the level of the striatum). At least three serial sections from three different animals for each genotype were photographed using an LSM710 confocal microscope or an Axio-Scan.Z1 slide scanner (Carl Zeiss). The number of relevant cells was calculated using the deep-learning algorithm Cellpose, which allows automatically counting cells in the cortex [15], or manually using the ImageJ. Nestin immunoreactivity was measured in each ROI as average fluorescence intensity.

Hematoxylin and eosin images analysis was carried out using NIH ImageJ software (Wayne Rasband, NINDS, $\mathrm{NIH}$ ). The following parameters were measured: area of brain slices; cortex thickness (perpendicular to the lateral ventricular region) and area of the lateral ventricles.

\section{Behavioral Assessment}

The study was conducted on mice of both sexes with genotypes $\mathrm{C} 215 \mathrm{Y} /+(\mathrm{n}=17), \mathrm{C} 215 \mathrm{Y} / \mathrm{C} 215 \mathrm{Y}(\mathrm{n}=6)$ and their $+/+(\mathrm{n}=8)$ littermates at the age of 8-12 weeks. Mice were left for $30 \mathrm{~min}$ prior to the experiment in the room to allow acclimatization.

\section{Open field test}

Mice were placed in a square open field $(42 \times 42 \mathrm{~cm})$ and were allowed to freely explore the open field for a $30-\mathrm{min}$ period in 11-lx illumination condition. Total distance traveled, velocity and spent time in center of arena during the session were automatically analyzed (Ethovision, Noldus). The arena was cleaned with $70 \%$ ethanol and dried between each test.

\section{Elevated plus maze}

The elevated plus maze consisted of a platform with four opposite arms $(40 \mathrm{~cm})$, two of them open and two closed (enclosed by $15 \mathrm{~cm}$ high walls). The apparatus was elevated at $55 \mathrm{~cm}$ from the floor. The task was recorded and analyzed with the software Ethovision (Noldus) and we measured the time spent in each arm in trials of $10 \mathrm{~min}$. The luminosity of the room was $11 \mathrm{~lx}$ in the open arms.

\section{Swimming tank test}

To measure swimming behavior, we used a swimming tank apparatus as previously described [16]. The tank was filled with water $\left(26-27^{\circ} \mathrm{C}\right)$ until the escape platform remained elevated 1-2 $\mathrm{cm}$ above the water level. At the opposite side of the tank, a vertical red line indicated the starting point located at $60 \mathrm{~cm}$ from the platform. The task consisted of three consecutive trials $(\sim 10 \mathrm{~s}$ between trails), performed daily from day 1 to 3 . We measured the time to swim the $60 \mathrm{~cm}$ of distance from the red line to the platform. The task was recorded and analyzed with the software VLC Media Player.

\section{Rotarod test}

To assess motor skills, we used the rotarod apparatus (Ugo Basile, Biological Research Apparatus) consisted of a plastic roller with small grooves running along its turning axis. Mice were subjected to two trials per day for four consecutive days with $20 \mathrm{~min}$ intervals between trials. The protocol included a classical accelerated rotarod [17] sequence ramping up from five rotations per minute (RPM) to $40 \mathrm{RPM}$ within $240 \mathrm{~s}$ for a maximum duration of $300 \mathrm{~s}$. We scored the mouse latency to fall in seconds of each last trial session per day. Mice that did not fall during experiment were assigned the time of $300 \mathrm{~s}$.

\section{Pole test}

The pole test was performed as previously described [18] with minor modifications. A $50 \mathrm{~cm}$ pole with a diameter of $10 \mathrm{~mm}$ was placed in animal cage. The mouse was put head-upward on the top of a vertical rough-surfaced pole; the time to descend to the floor and turn time at the end of the pole were measured. Experimental session consisted of 5 trials with $15 \mathrm{~s}$ interval trial break.

\section{Analysis of the $\mathrm{C} 215 \mathrm{Y} /+$ behavior by motion sequencing (MoSeq) algorithm}

The original Moseq script $[19,20]$ was obtained from Michael Schartner [21]. The MATLAB kinect recording script and MoSeq processing modules were modified to ensure recording at 30fps over the entire $20 \mathrm{~min}$ recording session and compatibility with Kinect 2 data. 
To ensure fps stability, the data over $20 \mathrm{~min}$ was acquired in $\sim 20 \mathrm{~s}$ periods followed by $1-2 \mathrm{~s}$ interruptions necessary for storage. Additionally, the manual preprocessing control step was added to allow monitoring and removal of several remaining mouse tracking and recognition artifacts. Overall, ten $C 215 Y /+$, five $C 215 Y / C 215 Y$ and six wild-type (wt) 2 months-old littermates were analyzed this way. PCA fit of the entire merged dataset was performed with 15 dimensions and subsequent state analysis by ARHMM with 15 states revealed that assignment of the states for the data set of this size had partially stochastic character. The fit was culminating at stable "equilibrium", unchanged by increased iteration number, but for each independent run this resulted in somewhat different assignment of the states for certain frames. This stochastic assignment was independent of PCA fit and states number in ARHMM model. Thus, in order to avoid bias resulting from choosing a single run to interpret and better delineate the syllable borders, we have performed 8 independent ARHMM model fits and thus obtained 8 independent values of states per frame as its unique syllable signature. $>50,000$ of such unique signatures were clustered via Scipy hierarchy clustering using WPGMA algorithm and manually split into 44 clusters obtaining final syllables. For these syllables we have subsequently evaluated frequency as a number of times it is called per minute of mouse activity, mean length of uninterrupted assignment in seconds and a total proportion of this syllable over the entire recorded time.

\section{Large-scale high-density electroencephalography (EEG)}

Surface epicranial EEGs were recorded in head-fixed, awake animals with a high-density grid of 32 stainless steel electrodes (see Additional file 1: Fig. S11A) covering the entire skull surface as described previously [22]. Briefly, a head-post was first placed under anesthesia (Medetomidin $5 \mathrm{mg} / \mathrm{kg}$ body weight (bw), Midazolam $5 \mathrm{mg} / \mathrm{kg}$ bw, Fentanyl $0.05 \mathrm{mg} / \mathrm{kg}$ bw) in order to allow head-fixation and the placement of the epicranial grid during the subsequent EEG recordings. Recording sessions then took place after a period of $4 \mathrm{~d}$ of head-fixation training to allow acclimatization of the animals to the experimental setup. Electrophysiological differential recordings were acquired during sessions of $1 \mathrm{~h}$ with a Digital Lynx SX (Neuralynx, USA) at a sampling rate of $4 \mathrm{kHz}$ and with a $2 \mathrm{kHz}$ low-pass. The ground electrode was placed above the nasal bone and the reference electrode was placed on the midline between parietal bones and all signals were then calculated against the average reference offline. EEG signals were then scrutinized by an experimenter blind to the animal condition (wt or mutant mouse) to detect the presence of paroxysmal discharges reminiscent of ictal or interictal-like activities using similar analyses tools as previously described previously [22]. In addition to the reviewer visual detection of seizure like patterns and epileptic spikes, we applied an automatic detection of fast ripples, a biomarker of epileptogenic brain regions [23, 24]. This detector identifies events with 4 consecutive oscillations 3 times higher in amplitude than the SD of the $250 \mathrm{~ms}$ surrounding baseline after filtering the EEG signals between 200 and $550 \mathrm{~Hz}$ using an order 2 Butterworth filter. All identified events were then visually confirmed in the filtered and unfiltered data as described in previous publications with the kainate mouse model [22].

\section{Pentylenetetrazol (PTZ)-induced convulsion test}

We used a PTZ kindling model of epilepsy to achieve a sub-convulsionary state [25]. Briefly, $\mathrm{C} 215 \mathrm{Y} /+$ and $+/+$ mice were injected with two doses of 30 and $35 \mathrm{mg} / \mathrm{kg}$ every other day of PTZ (Sigma, P6500) which were enough to achieve a sub-convulsionary state for both genotypes. The mice were scored over a period of 30 min after PTZ injection according to the intensity of the behavioral seizure as described [26].

\section{Results}

G203R mutation in the GNAO1 gene demonstrates early postnatal lethality

We first attempted to create G203R (c.607G > A)-bearing mutant mice using the CRISPR/Cas9-based technique (see Materials and Methods). We performed 3 injection sessions of the CRISPR-Cas9 reagents and template designed to introduce target mutation in the mouse GNAO1 gene. The results are summarized in the survival graph (Fig. 1A). Overall, we obtained 9 homozygous $(G 203 R / G 203 R)$ and 7 heterozygous $(G 203 R /+)$ F0 pups. All of the homozygous pups were dead within one day after birth, whereas 2 out of 7 heterozygous pups survived until P4 and P14 and were found spontaneously dead without signs of external damage. Of the littermates, the pups surviving until weaning were either $+/+(\mathrm{wt} /$ $\mathrm{wt}$ ) or contained a wild-type (wt) and a truncated allele of GNAO1 resulting from CRISPR-mediated indels.

In parallel, we attempted to similarly introduce the C215Y (c.644G > A) point mutation. The resultant F0 mice and progeny were viable and fertile, both as heterozygotes and as homozygotes (Fig. 1B). As a by-product of the trangenesis, GNAO1 ${ }^{-1-}$ loss-of-function (homozygous for indel mutations leading to truncated unfunctional protein) animals were generated, showing a reduced survival (Fig. 1B) in accordance with earlier reports [27]. The normal viability and fertility of the mutant C215Y GNAO1 mice permitted us to establish a stable colony and to perform a set of behavioral experiments, detailed below. 

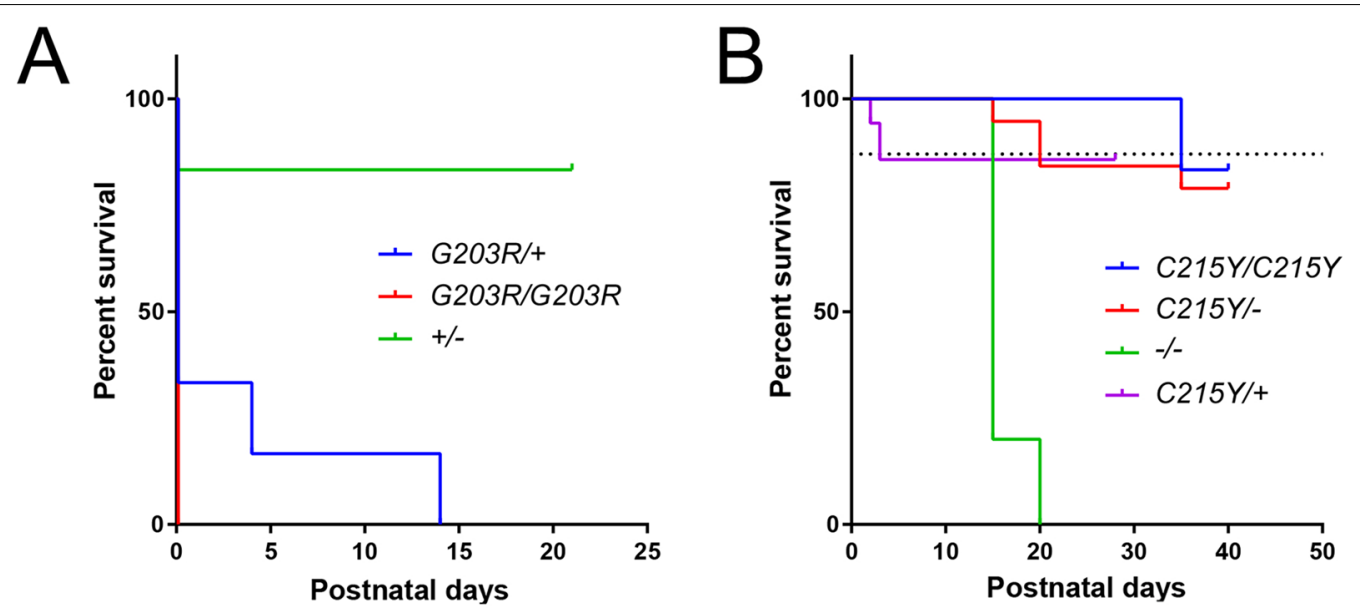

Fig. 1 Survival rate of F0 mice of different genotypes after transgenesis. A G203R F0 mice, either homozygous or heterozygous, reveal dramatic postnatal lethality. Only two G203R/ + mice lived past postnatal day 1. B In contrast, heterozygous or even homozygous F0 G215Y mice revealed the survival not different from fully wt mice (dotted line). GNAO1 ${ }^{-1-}$ loss-of-function animals generated as a by-product of the transgenesis showed reduced survival. "-" designates a truncated allele resulting from CRISPR-mediated indels

Additional file 1: Fig. S1 shows the proper expression of the mutant (G203R and C215Y) alleles, alongside with the wt allele, in the mutant animals. Note that the peak height of the mutant nucleotide is nearly identical to that of wt in both mutants, speaking of near-equal expression of both alleles. Taken together, these findings prove that the G203R mutation-unlike the C215Y mutation-even in heterozygous state is postnatally lethal.

\section{C215Y mutation leads to altered brain morphology in E18.5 embryos}

Abnormal structure and function of the cerebral cortex have been reported across studies of patients with GNAO1 mutations [1, 2, 5-7]. Thus, in the newly created disease model based on the $\mathrm{C} 215 \mathrm{Y}$ mutation we first analyzed the brain morphology. Considering that the G203R mutation is lethal in the early postnatal stage, we chose to analyze embryos at the late gestation age of 18.5 days to allow eventual comparison between the two models (see below) while approaching the brain development level of new-born humans. We analyzed the coronal brain sections of heterozygous $(C 215 Y /+)$, homozygous $(C 215 Y /$ $C 215 Y$ ) and wt littermates at 18.5 days of gestation stained with H\&E (Fig. 2A), and quantified the areas of the brain slices and the size of lateral ventricles. No significant difference in the area of the coronal section of the brain was found across the genotypes (Fig. 2B). The lateral ventricles were significantly enlarged in the $C 215 Y /+$ and C215Y/C215Y mice compared with those of the wt littermates (Fig. 2C). Subsequent analysis revealed differences in the motor cortex thickness between $C 215 Y / C 215 Y$ and wt littermates (Fig. 2D,E). To evaluate whether the cell numbers were changed in the entire cortex, the total number of cortical cells was quantified by the deep learning-based segmentation algorithm Cellpose [15] in brain slices stained with DAPI, revealing a significant decrease in the cell densities in the two mutant genotypes (Fig. 2F) while keeping the cell numbers unchanged (ca. 12,000 cells for each genotype).

In opposite to the changes in the cortex induced by the C215Y mutation, we did not find aberrations in two other brain regions analyzed: striatum (Additional file 1: Fig. S2) and hippocampus (Additional file 1: Fig. S3).

\section{Reduced numbers of cortical progenitor cells underlie brain morphology aberrations in $\mathrm{C} 215 \mathrm{Y}$ mutants}

Complete knockout of GNAO1 impaired the cerebellar cortical development in mice [28] asserting key role of Goo in brain compartment development. We thus investigated the potential influence of the $\mathrm{C} 215 \mathrm{Y}$ mutation in brain development, particularly in the context of the cortex. Changes in the cellular composition in the cortex of mice bearing the $\mathrm{C} 215 \mathrm{Y}$ mutation were analyzed quantitatively looking at different cell markers in each layer of the cortex at the stage E18.5 [29]. Projection neurons residing in deeper layers of the cortex were stained by Tbr1 (layer VI) and Ctip2 (layer V); upper layers were analyzed using Brn2 (present in layers V to II but mostly present in the layers II/III) and Reelin for identification of 

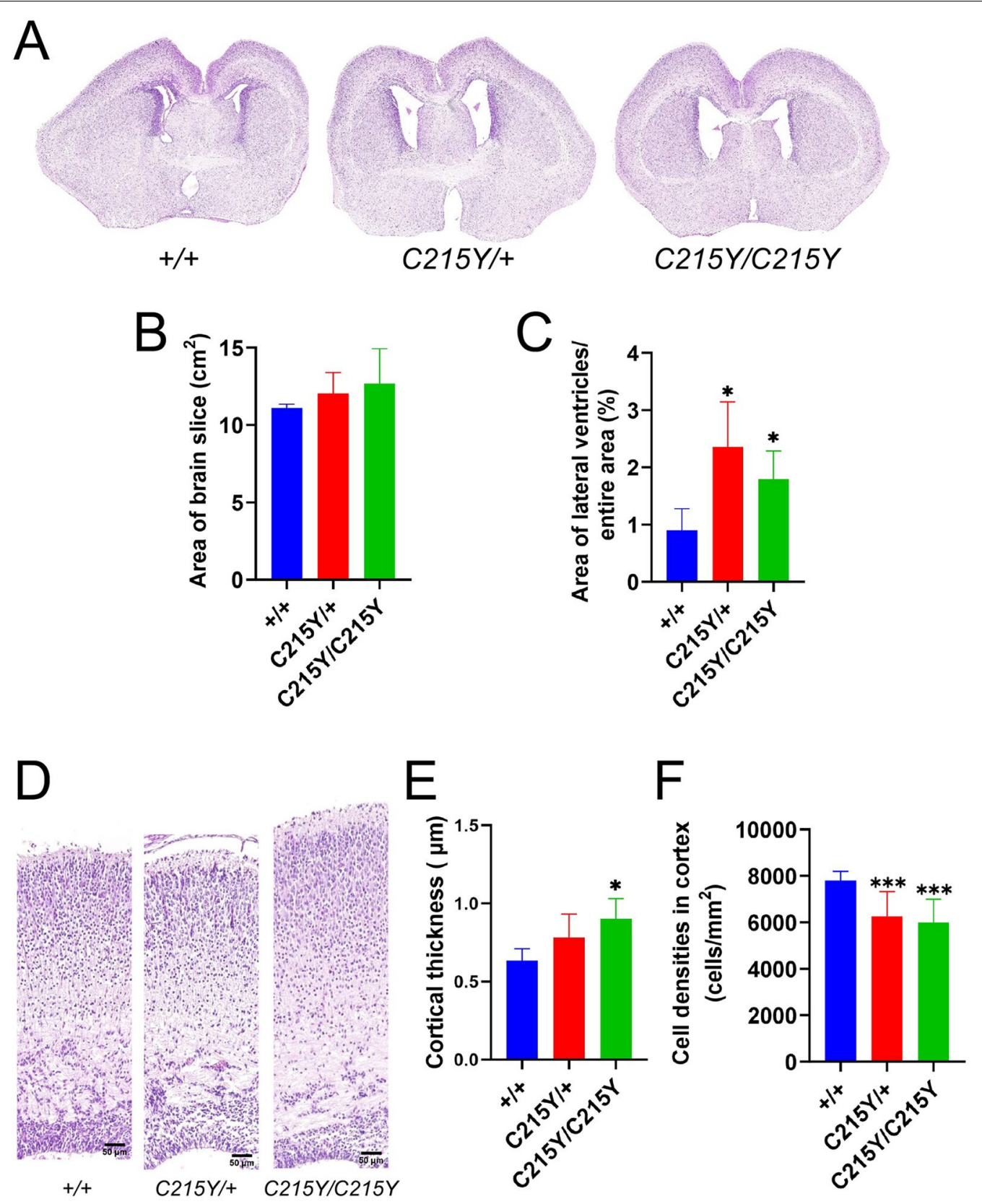

Fig. 2 Effects of homo- and heterozygous C215Y mutation on brain morphology. A-C Hematoxylin and eosin staining of coronal brain sections from C215Y/+, C215Y/C215Y, and wt (+/+) littermates at the embryonic day 18.5 (A) reveals insignificant changes in the overall brain area (B) but enlarged lateral ventricles in the mutants (C). D-F Coronal sections through the motor cortex (D) show differences in the cortical thickness between wt and C215Y/C215Y mice (E). Quantification of the cell density in this region reveals that it is decreased in the two mutant genotypes (F). Data are presented as mean $\pm \mathrm{SD}, \mathrm{n}=3-5$ animals. ${ }^{*} p<0.05,{ }^{* *} p<0.01,{ }^{* *} p<0.005$, significance from the wt is assessed by t-test. Scale bar: $50 \mu \mathrm{m}$

(See figure on next page.)

Fig. 3 C215Y mice show decreased number of neurons in deep layers of the cortex. A-C Staining of motor cortex brain sections from E18.5 wt $(+/+, \mathbf{A}), C 215 Y /+(\mathbf{B})$, and C215Y/C215Y (C) mice for DAPI (blue), Tbr1 (layer VI, red), and Ctip2 (weak in layer VI, strong in layer V, green). D Quantification of Tbr1-positive cells' density. E Quantification of Ctip2-positive cells' density. Data are presented as mean $\pm S D ; n=3-5$ animals; ${ }^{* *} p<0.01,{ }^{* * *} p<0.005$, significance from the wt is assessed by t-test. Scale bar: $50 \mu \mathrm{m}$ 

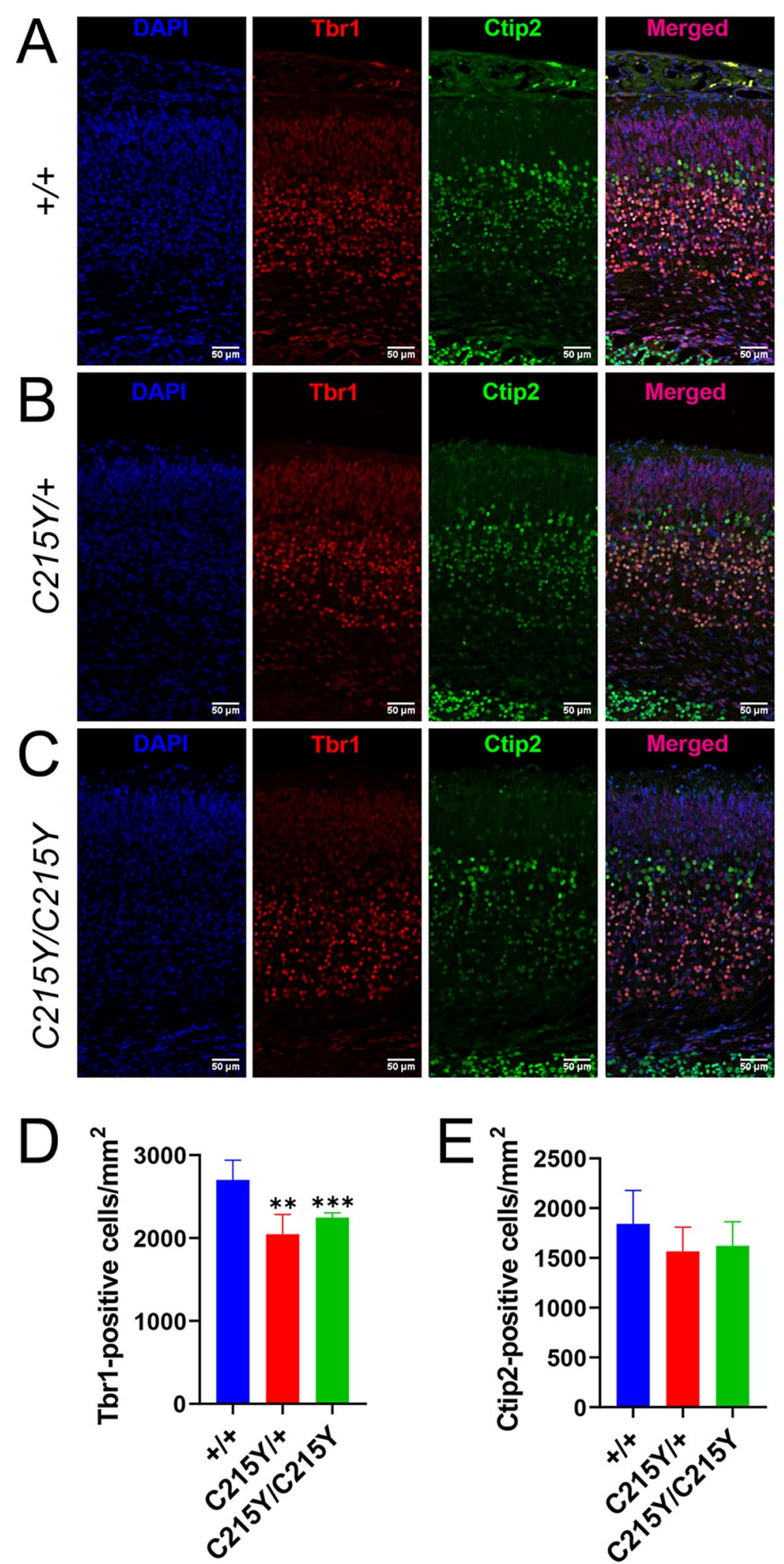

Fig. 3 (See legend on previous page.) 
Cajal-Retzius cells lying in the most superficial molecular layer [30, 31].

We found that the layer VI (Tbr1-positive), the deepest and the first to be generated during brain development, had significantly lesser cell density in both homozygous and heterozygous $C 215 Y$ mice compared to their wt littermates (Fig. 3A-D). In contrast, we found no statistically significant difference in the number of Ctip2-positive cells in the layer V (Fig. 3A-C,E). A decrease in the number of Brn2-positive cells in layers II-V was seen in the mutant genotypes, becoming statistically significant for the homozygous mutants (Additional file 1: Fig. S4A, C). In the molecular layer of the cortex, there was a similar trend of decreased numbers of the Cajal-Retzius cells marked by Reelin, with the difference from the wt being statistically significant for the homozygous $C 215 Y / C 215 Y$ mice (Additional file 1: Fig. S4B, D).

The changes we identified in the number of cells in the layers of the cortex prompted us to investigate progenitor cells for projection neurons (Fig. 4). We assessed the radial glial cells lining the lateral ventricular zone by staining for Nestin and the intermediate progenitors using the Tbr2 marker. We observed a marked decrease in the cortical thickness in lateral ventricle regions in $C 215 Y$ mice of both homozygous and heterozygous genotypes compared to the wt littermates (Fig. 4A-D). However, intensity of the Nestin staining remained unchanged, which taken together with the overall reduction of thickness indicated a decrease in the total number of radial glial cells, rather than a change in tissue compactness (Fig. 4E). Importantly, the $C 215 Y /+$ and $C 215 Y / C 215 Y$ mice demonstrated nearly halved numbers of the Tbr2-positive cells in the ventricular and subventricular zone compared to wt littermates (Fig. 4A-C,F).

Thus, we conclude that the $\mathrm{C} 215 \mathrm{Y}$ mutation in both heterozygous and homozygous states leads to impaired brain development mainly due to reduced numbers of the neural progenitor cells-that in turn could be an outcome of impaired differentiation or migration, but not increased apoptosis, as anti-caspase 3 staining in the cortical plate, the subventricular and the ventricular zone did not reveal any differences across the genotypes (Additional file 1: Fig. S5).

\section{Brain morphology and cortex structure of G203R E18.5 embryos reveal similarities with the $C 215 Y$ phenotypes} Since the GNAO1[G203R/+] line could not be established due to the postnatal mortality (Fig. 1A), we processed E18.5 embryos of this genotype for IHC analysis directly after CRISPR/Cas9 transgenesis. In this manner, post-transgenesis embryos were fixed and then genotyped. Inevitably, this approach could not generate controllable and large numbers of specimen of the right genotype. In our attempt, we could generate one G203R/+ and two G203R/G203R E18.5 fixed embryos. Although insufficient for statistical analysis, these experiments were deemed worthy of a qualitative "case report", relevant for the current study as they permit comparisons with the $C 215 Y$ animals and generalizations important to understand the disease. We thus proceeded with analysis of the G203R mutant animals in a manner similar we described above to $C 215 Y$ E18.5 embryos.

H\&E staining of coronal brain slices revealed strong morphological defects, such as a decrease in the brain section area in $G 203 R / G 203 R$ embryos and the increase in the lateral ventricle size in $G 203 R /+$, the latter is similar to that in $C 215 Y$ embryos (Additional file 1: Fig. S6A). In contrast to $C 215 Y$, however, the cortex thickness dropped in G203R/+ (but not in homozygous mutants, Additional file 1: S6B). Further analysis of projection neurons in deeper layers of the cortex (Additional file 1: S6C) did not reveal changes in numbers of Ctip2-positive cells between $\mathrm{G} 203 R /+\left(2052\right.$ cells $\left./ \mathrm{mm}^{2}\right)$, G203R/G203R $\left(2263 \pm 149\right.$ cells $/ \mathrm{mm}^{2}$, mean $\left.\pm \mathrm{SD}\right)$, as compared to the wt embryos $\left(1842 \pm 168\right.$ cells $\left./ \mathrm{mm}^{2}\right)$.

In contrast, the number of Tbr1-positive cells strongly decreased, from $2702 \pm 119$ cells $/ \mathrm{mm}^{2}$ in the wt to 1640 cells $/ \mathrm{mm}^{2}$ in the $G 203 R /+$ and $2342 \pm 323$ cells $/ \mathrm{mm}^{2}$ in $G 203 R / G 203 R$, similar to the finding for the $C 215 Y$ genotypes. We further counted the number of Brn2positive cells that identify the upper layers. In $G 203 R /+$, the number of Brn2-positive neurons (5048 cells $/ \mathrm{mm}^{2}$ ) increased as compared to G203R/G203R (3714 \pm 952 cells $\left./ \mathrm{mm}^{2}\right)$ and wt $\left(3143 \pm 287\right.$ cells $\left./ \mathrm{mm}^{2}\right)$ for II/III layers. Reelin-positive cells in the marginal zone of G203R/ G203R ( $33 \pm 6$ cells $/ \mathrm{mm}$ ) were more numerous than in $\mathrm{G} 203 R /+(21$ cells $/ \mathrm{mm})$ and wt $(23 \pm 2$ cells $/ \mathrm{mm})$.

To assess whether these differences in the number of neurons in the cerebral cortex in G203R mutant mice could be due to developmental defects of neural progenitor cells, radial glial cells positive for Nestin and intermediate neuronal precursors positive for Tbr2 were evaluated, revealing a reduction in the ventricular zone thickness from $81.2 \pm 2.2 \mu \mathrm{m}$ for wt to $54.1 \mu \mathrm{m}$ in $G 203 R /+$ and $53.9 \mu \mathrm{m}$ in the homozygous mutants. While we did not find any differences in the intensity of Nestin staining, the Tbr $2+$ precursors were decreased in the G203R mutants: from $6533 \pm 437$ cells $/ \mathrm{mm}^{2}$ in the wt to 3600 cells $/ \mathrm{mm}^{2}$ in $G 203 R /+$ and $5750 \pm 1626$ cells/ $\mathrm{mm}^{2}$ in G203R/G203R.

Comparison of the $C 215 Y$ and G203R demonstrates that there is a drop in the thickness of lateral ventricle cortex and the number of Tbr1-positive and Tbr2-positive cells in both genotypes; both mutations also decrease the number of neural progenitor cells. These features highlight a common neurodevelopmental defect at the basis of the two dominant GNAO1 mutations. 


\section{Assessment of behavioral and motor disorders in mice with the C215Y mutation}

For the patients with the $C 215 Y /+$ mutation, the reported symptoms are almost exclusively related to the motor disfunctions (Table 1) [8, 9]. We therefore chose a set of behavioral tests to characterize exploratory and motor functionalities in mice with the $C 215 Y$ mutation. The open field was used to assay exploratory behavior and general locomotor activity in mice during $30 \mathrm{~min}$. The analysis was divided in 3 stages, $10 \mathrm{~min}$ each, thus we separately evaluated the activity during the initial time period (0-10 $\mathrm{min}$ ) corresponding to the exploratory activity, while the sustained locomotor activity was assessed by analysis over the entire interval of $30 \mathrm{~min}$. We found that both the exploratory activity and the sustained activity were significantly increased for the heterozygous and homozygous $C 215 Y$ mice, this effect being apparent as increase in the distance travelled and the speed of locomotion by the mutant mice (Fig. 5A-C). Homozygous mice also had significantly decreased spent time in the center of the arena compared with $+/+$ and $\mathrm{C} 215 \mathrm{Y} /+$ mice that may indicate anxiety-like behavior (Additional file 1: Fig. S7A).

Since mice of both $C 215 Y$ genotypes showed hyperactivity in the open field test, we decided to evaluate the efficacy of risperidone as an antipsychotic drug and a drug prescribed to reduce hyperkinetic movement disorders. This drug has been shown to be effective in some patients with GNAO1-encephalopathy [32]. We analyzed the effects of risperidone on the behavior of the mutant animals, finding that injection of $2 \mathrm{mg} / \mathrm{kg}$ or even $0.5 \mathrm{mg} / \mathrm{kg}$ risperidone (the dosages used in the GNAO1[R209H/+] mouse study [33]) resulted in a complete immobilization of the animals for around $30 \mathrm{~min}$ (data not shown). The reduced dose of $0.1 \mathrm{mg} / \mathrm{kg}$ decreased the motor activity scores by several folds as compared to the vehicle-treated ones. Noteworthy, $C 215 Y$ heterozygotes still presented statistically significant hyperactivity as compared to wt (Additional file 1: Fig. S7B; homozygotes were not tested in these experiments) - the feature also seen in the GNAO1[R209H/+] mouse study [33].

We also used the swimming tank test for monitoring the complex swimming activity. Interestingly, the $C 215 Y /+$ mice demonstrated a significantly increased velocity in this test (Fig. 5D). Next, the accelerating rotarod test was used to assess motor coordination and balance in mice, revealing that the motor-coordination parameters of $\mathrm{C} 215 \mathrm{Y} /+$ mice were more effective than those of the wt mice (Fig. 5E). The pole test aimed at estimating the eventual bradykinesia in mice with mutations did not reveal any influence of the genotype on performance in this test (Additional file 1: Fig. S7C). Finally, the elevated plus maze test was applied to evaluate whether the $C 215 Y$ mice presented an anxiety phenotype. We found that the homozygous mice spent less time in the open arms compared with wt (Fig. 5F), suggesting an anxiety-like phenotype which was also inferred from the open field test (Additional file 1: Fig. S7A).

\section{Quantitative analysis by MoSeq conforms the hyperlocomotive changes in the steady-state adult mouse behavior upon GNAO1[C215Y] mutations}

Visually, the standard behavior of the $C 215 Y /+$ and $C 215 Y / C 215 Y$ did not differ from that of the wt littermates, unless specific behavioral tests were applied as described above. To track eventual modest locomotor dysfunctions in the routine mouse behavior, we modified the MoSeq algorithm $[19,20]$ as described in Materials and Methods to perform an unbiased in-depth investigation of the behavioral patterns in different genotypes. This MoSeq analysis identified 44 principal behavioral syllables that we manually assigned to interpretable patterns (e.g. Forward Move 1, Sitting 2, etc.) to simplify their grouping and representation (Additional file 1: Fig. S8). Each of the syllables was characterized by three principal characteristics: (i) frequency $\left(\mathrm{min}^{-1}\right)$ as the measure of how often the syllable is initiated by the animal per minute of activity; (ii) mean length (sec) as the average duration of an uninterrupted syllable; (iii) proportion (\%) as the overall percentage of time the animal used a given syllable over the entire period of recording.

We performed a robust statistical analysis of these characteristics of syllables between females of $C 215 Y /+, C 215 Y / C 215 Y$, and the littermate wt genotypes (Additional file 1: Figs. S8 and S9). The most notable observation is a significant decrease in the C215Y mutants of the proportion of syllables \#26 and \#32 (Sitting 8 and Sitting 10), being the main sitting

(See figure on next page.)

Fig. 4 C215Y mutation in GNAO1 gene affects cortical neural progenitor cells. A-C Staining of brain sections of ventricular and subventricular cortical zones from E18.5 wt $(+/+, A), C 215 Y /+(B)$, and C215Y/C215Y (C) mice for DAPI (blue), Nestin (green) or Tbr2 (red). D Measurement of the ventricular zone thickness. E Quantification of the Nestin staining intensity. F Quantification of Tbr2-positive cells. Data are presented as mean \pm SD, $\mathrm{n}=3-5$ animals. ${ }^{*} p<0.05,{ }^{* *} p<0.01$, significance from the wt is assessed by t-test. Scale bar: $20 \mu \mathrm{m}$ 


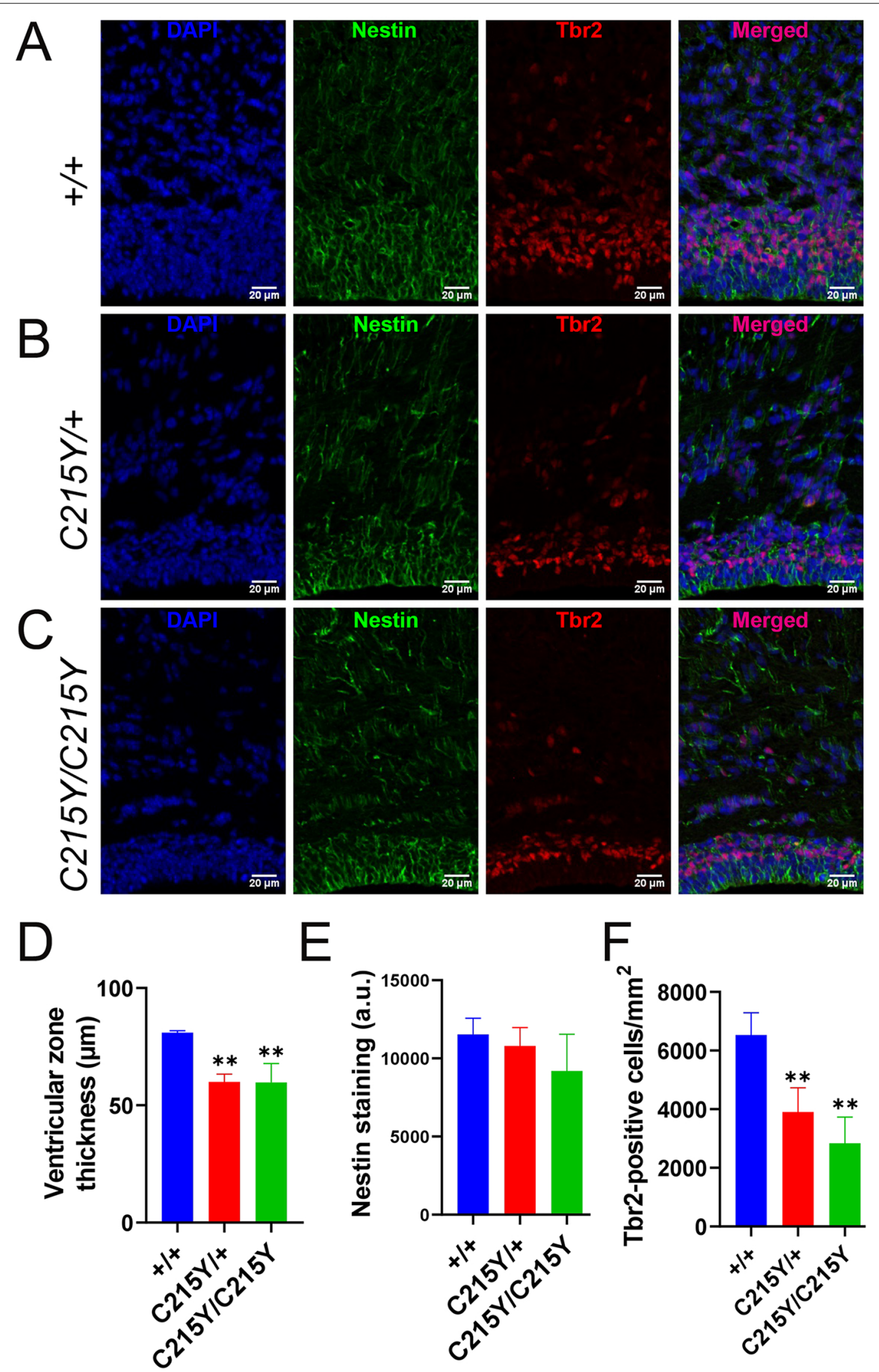

Fig. 4 (See legend on previous page.) 
postures of the animals. This decrease correlates with the allele number. For these syllables, in $C 215 Y / C 215 Y$ mice we also observed the corresponding increase in their frequency, and for the syllable 26-an additional drop in its mean length (Additional file 1: Fig. S9). This indicates that the mutation reduces the time the mice are motionless, which is additionally corroborated by the respective growth of the frequency and the proportion of the syllable \#28 (Forward move 8) designating nearly half of the forward moves of the animals, and of the syllable \#1 (Rearing stand 1). Interestingly, while the homozygous animals perform syllable \#1 (Rearing stand 1) more frequently and more often, the heterozygous ones demonstrate a significantly increased length of the stand.

Additional information could be obtained from the network analysis, where the nodes represent syllables and edges-transitions between them. On the Additional file 1: S10A-C, the size of the node and its label represent the syllable proportion as shown in the Additional file 1: Fig. S8, while the edge thickness corresponds to the proportion of a given transition relatively to the entire number of syllable transitions in the animals' behavior. We observed that syllables \#26 and \#32 (Sitting 8 and Sitting 10) are frequently interchanged in wt mice with nearly $2 \%$ of all pattern transitions occurring only between these two. However, in the $C 215 Y /+$ and $C 215 Y / C 215 Y$ animals this proportion is reduced and the animals are more frequently transiting into other syllables, e.g. related to forward movements or rearing, which is reflected by the growth in transitions between syllables \#27 and 28 (Forward moves 7 and 8), or \#32 and \#7 (Sitting 10 to Forward move 7). Interestingly, while both syllables \#26 and \#32 (Sitting 8 and Sitting 10) are decreased in the mutants, the proportion of only one type of the forward move is affected, indicating that this hyperlocomotive behavior is specific for a particular type of movement (Additional file 1 : $\mathrm{S} 10 \mathrm{~B}, \mathrm{C})$.

In summary, this deep behavioral analysis makes it clear that the $C 215 Y$ mutant animals exert the hyperlocomotive behavior also under the unchallenged conditions by reducing the movement patterns associated with sitting and increasing those associated with forward moves. The number and significance of the behavioral changes observed correlate with the allele number: $C 215 Y /+$ animals score overall 7 significant differences in syllable characteristics as compared to the wt, with this number growing to 23 for the $C 215 Y / C 215 Y$ animals. Altogether, this in-depth analysis of the regular mouse behavior corroborates the findings of the dedicated behavioral tests: $C 215 Y$ mutant mice are hyperactive and hyperlocomotive. This phenotype can be viewed as the mouse analog of the excessive and uncontrolled motor activity of human GNAO1[C215Y/+] patients (Table 1) $[8,9]$.

\section{Lack of epileptic manifestations in $\mathrm{C2} 15 \mathrm{Y} /+$ animals}

Patients carrying the C215Y GNAO1 mutation do not reveal signs of epilepsy [8,9] (Table 1), unlike patients with several other point mutations in GNAO1. In agreement with these clinical findings, we did not observe any signs of behavioral seizures (such as facial automatisms, myoclonus, jumping and running or tail or hindlimb extension) in $C 215 Y /+$ or $C 215 Y / C 215 Y$ mice during the animal handling and behavioral assessment procedures. To corroborate on these phenotypic observations, electroencephalography (EEG) recordings were performed on wt and C215Y/+ mice (see Materials and Methods), that did not reveal any epilepsy-related activity in either genotype (Additional file 1: Fig. S11A-C). Careful visual inspection of the EEG sessions did not reveal any epileptiform episodes such as seizure-like or other types of pathological patterns reminiscent of paroxysmal discharges in controls and in the mutant mice. We did not observe alterations in the EEG activities as compared to the control wt mice. Measuring the number of fastripples (FRs) at all surface electrodes in 3 controls and 3 mutant mice, FRs were only detected at electrodes above the somatosensory regions in both genotypes and at a similar range (median and IQ range: Control: 0.16, 0.11,

\footnotetext{
(See figure on next page.)

Fig. 5 Assessment of behavioral and motor disorders in mice with the C215Y mutation. A-C C215Y/+, and even more so the homozygous C215Y/ C215Y mice, display hyperlocomotion in the open field test. Data are shown as the distance moved by a mouse (A) and the velocity of the mouse (B) for the two mutant genotypes and their wt littermates, measured in the 0-10 min, 10-20 min, 20-30 min intervals of the experiment, and the overall 0-30 min of the experiment. Representative trail plots are shown in (C). D C215Y/ + mice outperformed the wt littermates in the swimming test. $\mathbf{E}$ In the rotarod test, $C 215 Y /+$ mice outperformed their wt littermates. Quantification of the time to fall parameter over the four days of the experiments is shown. $\mathbf{F}$ Group mean of the time in open arms in the elevated plus maze for the three genotypes. In all panels data is given as

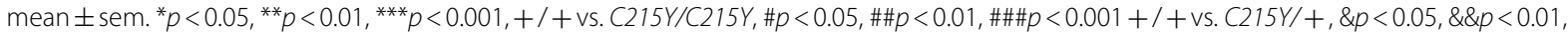
$\& \& \& p<0.001 \mathrm{C} 215 \mathrm{Y} /+$ vs. $C 215 Y / C 215 Y$ as determined by two-way ANOVA with Dunnett's multiple comparison test $(\mathbf{A}, \mathbf{B}, \mathbf{D}, \mathbf{E})$ and $\mathrm{t}$-test $(\mathbf{F}) ; n=8$ (wt), $17(C 215 Y /+)$ and $6(C 215 Y / C 215 Y)$ mice
} 


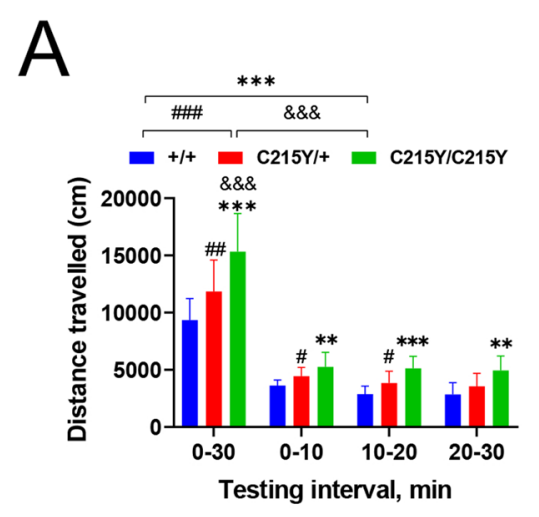

D

Swimming tank test

$60 \mathrm{~cm}$ from red line to platform;

3 trials per day without break during 3 days
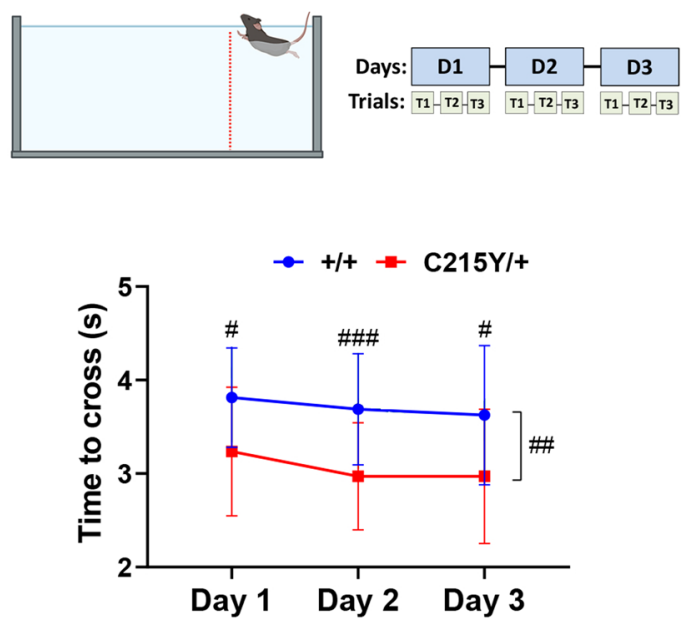

F
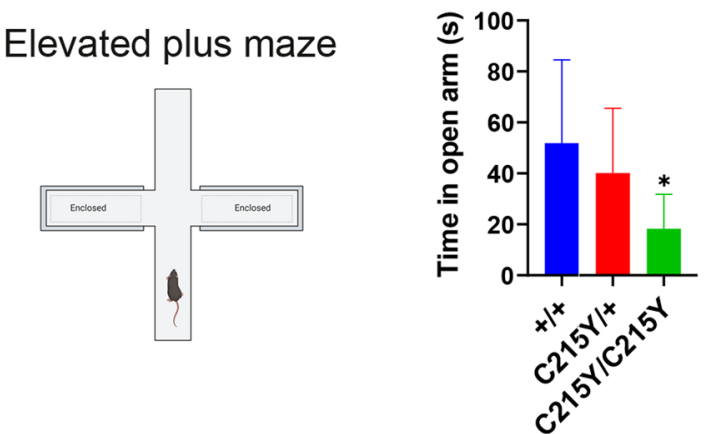

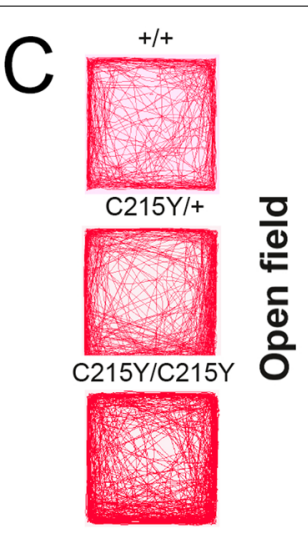

\section{Rotarod test}

5 RPM to 40 RPM; $300 \mathrm{~s}$; 2 trials per day with 20 min break

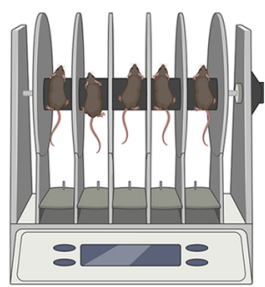

Days: D1 D2 D3 D4

Trials: $\begin{array}{lllll}\mathrm{T} 1-\mathrm{T}_{2} & \mathrm{~T} 1-\mathrm{T} 2 & \mathrm{~T} 1-\mathrm{T} 2 & \mathrm{T1} 1-\mathrm{T} 2\end{array}$

$\rightarrow \quad 1+\rightarrow \mathrm{C} 215 \mathrm{Y} /+$

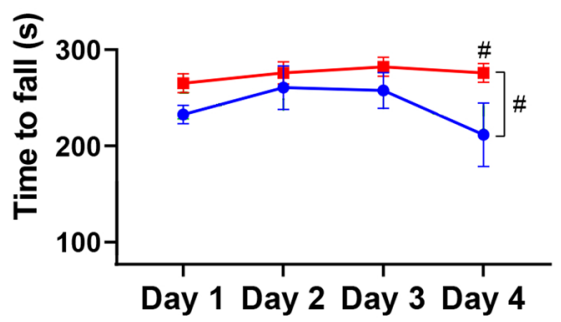

Fig. 5 (See legend on previous page.)
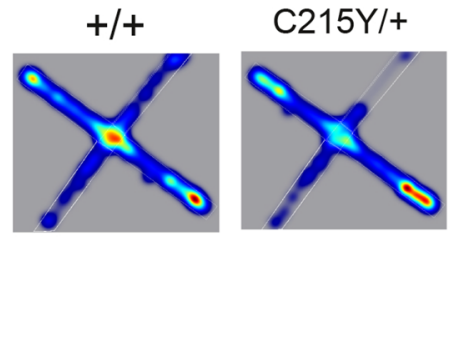

C215Y/C215Y

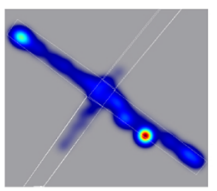


0.3 ; Mutant: $0.2,0.03,0.23)$ suggesting that only physiological FRs were detected.

To further investigate the epileptic potential of the $\mathrm{C} 215 \mathrm{Y} /+$ mice, we performed the pentylenetetrazole (PTZ)-induced kindling experiment (Additional file 1: Fig. S11D). As Additional file 1: Fig. S11E reveals, at two increasing doses of PTZ, seizures were progressively induced, but the seizure score was indistinguishable between the $C 215 Y /+$ mice and their wt littermates.

\section{Discussion}

First reported in 2013, dominant mutations in GNAO1 cause a spectrum of early-onset neurological deficiencies in affected children, encompassing, depending on the exact mutation, severe motor disabilities, epileptic seizures, developmental delay, intellectual disability, and progressive brain atrophy [1-4]. The patients often require intensive care after birth, as well as gastrostomy due to difficulties in feeding $[1,3]$. As of today, no curative therapy exists for GNAO1 encephalopathy patients, with symptomatic treatments at best demonstrating partial and temporary effects $[3,10,11]$.

Proper animal models are instrumental to decipher disease mechanisms and to develop eventual treatment regimens. GNAO1 encephalopathy patients harbor one wt and one mutant allele of GNAO1; as the majority of the clinical cases described do not reveal mosaicism [2, $4,7,11,34]$, the de novo mutations in GNAO1 supposedly arise in the gamete of one of the parents. Thus, the resulting dominant action of the pathogenic point mutation affects the patient development-and primarily the patient's CNS development-through all stages of embryonic and postnatal development. Further, equal (or at least similar) levels of expression of the mutant and $\mathrm{wt}$ GNAO1 variants are observed (see Additional file 1: Fig. $\mathrm{S} 1$ or [33]). These considerations imply that mere overor mis-expression of a mutant GNAO1, either ubiquitous or restricted to a particular brain area or a particular developmental time window, cannot represent a model adequately recapitulating the human patients. Such an adequate animal model of GNAO1 encephalopathy can only be generated through introduction (e.g. with CRISPR/Cas9) of the exact pathogenic point mutation into one allele of the endogenous GNAO1 locus, keeping the other allele and the expression control mechanisms intact, and observing the resultant dominant phenotypes. Such an approach has so far been proven successful in two studies in mice: an GNAO1[R209H]/+ mouse model [33] and the two mouse models described in the current manuscript: GNAO1[G203R]/ + and GNAO1[C215Y]/+. Further, similar modeling has proven successful in Drosophila (Goo[G203R]/ + model with reduced locomotion and life span, responding to a pharmacological rescue [35]). The modeling of GNAO1 encephalopathy has also been performed in C.elegans, with the nematodes heterozygous for S47G or A221D mutations revealing the dominant "unlaid eggs" phenotype indicative of effects in motor neurons, while the heterozygous G42R or R209C mutations produced the dominant aldicarb hypersensitivity effects [36, 37]. In contrast to these knock-in modeling, over/mis-expression of mutant Goo on top of the two wt alleles can be envisioned. For example, overexpression of Goo[G203R] or Goo[R209C] in striatal neurons has resulted in impaired locomotor behavior in mice [38]. This simplified approach may serve as a tool to provide insights on the functioning of the $G$ protein and its mutants [38], but its relevance as the disease model is unclear. It is interesting to note in this regard that the hyperactivity we observe in the $C 215 Y /+$ mice is not associated with anatomical defects in the striatum (Additional file 1: Fig. S2) but in the motor cortex (Fig. 2).

The two mouse models created and analyzed in our current study represent human patients at the two extremes of the GNAO1 encephalopathy clinical manifestation spectrum. On the one hand, G203R is one of the hotspot mutations in the disease that leads to the strongest and earliest in the onset deficiencies combining both motor dysfunctions and epileptic seizures, further accompanied by developmental delay and intellectual disability. On the other side of the spectrum, C215Y mutations lead to neither epilepsy nor developmental/intellectual delays, but present clinically with motor abnormalities that manifest much later in life. These differences in the clinical manifestations of the two mutations are fairly reflected in the mouse models already at the level of the survival. Indeed, G203R/+mice are neonatally lethal with the longest surviving pups reaching the age of 14 and 4 days. Although this severe neonatal lethality did not permit assessment of eventual epileptic seizures, it is worth mentioning that another mouse modelGNAO1[G184S]/+ harboring an activating mutation not seen in human patients-displayed spontaneous lethality preceded by seizures [39]. In contrast, $C 215 Y /+$ mice are viable and fertile. Not revealing any epileptic phenotypes, the $C 215 Y /+$ mice proved hyperactive and hyperlocomotive in a broad panel of behavioral tests, similarly to the previously described $R 209 \mathrm{H} /+$ mouse model [33]; the homozygous loss-of-function $G N A O 1^{-/-}$mice also have been reported to display hyperactivity [27]. Uniquely, we could observe this hyperactivity not only in the standard tests like the open field or swimming tests, but also upon analysis of the unchallenged mouse behavior, assessed indepth through a dedicated MoSeq video monitoring and 
analysis algorithm we customized explicitly for this study. This hyperlocomotion, seizure-free phenotype can be viewed as the mouse analog of the excessive and uncontrolled motor activity of the human $C 215 Y$ patients [8, 9], similarly to the R209H mutation in patients and mice that leads to motor dysfunction but not epilepsy [33].

Regional brain malformations and atrophy, sometimes progressive, have been described in GNAO1 patients [5, $6,11,40-42]$. It has so far been impossible, however, to decode whether these malformations are the cause or the consequence of brain malfunctioning such as epileptic onsets. In a broader sense, it has been unknown if (and to which extent) GNAO1 encephalopathy is a neurodevelopmental disorder. In our study, we provide the first insights into this key aspect of the disease etiology. Remarkably, in both the G203R and C215Y mouse models, despite the differences we observed among them, significant prenatal brain development defects could be identified. These defects manifested in strong enlargement of lateral ventricles and reduced numbers of Tbr1-positive and Tbr2positive cells. The decrease in the neural progenitor cells could result from impaired differentiation or migration (but not increased apoptosis, see Additional file 1: Fig. S5). Interestingly, we recently described a GNAO1[Q52R] patient with periventricular nodular heterotopia seen on MRI, that represented a focal neuronal migration defect [11]. The commonality of neurodevelopmental abnormalities in the two mutants, despite their distinct behavioral and clinical manifestations, highlights a common neurodevelopmental defect at the basis of the two dominant GNAO1 mutations and potentially of GNAO1 encephalopathies in general. The fact that at later stages the two mutants deviate from each other into a mild encephalopathy (C215Y) vs. a severe one (G203R) both in patients and in mice may suggest that the Goo-controlled biochemical / physiological processes continue to be affected postnatally, differently for the two mutations. It might also be hypothesized that the neurodevelopmental abnormalities in the motor cortex, common for the two GNAO1 mutations, represent the 'basic' misfunction in GNAO1 encephalopathy and underlie the movement defects in the patients. Further aberrations 'added' later in development in the carriers of more severe mutations such as G203R then mediate additional defects like epilepsy.

Our work thus provides crucial insights into the etiology of this rare yet devastating disease, identifying it as to a large extent neurodevelopmental disorder. This understanding and the animal models we established shed light on the normal and pathological roles of Goo in the nervous system and will pave the way for eventual therapeutic developments.

\section{Supplementary Information}

The online version contains supplementary material available at https://doi. org/10.1186/s40478-022-01312-z.

Additional file 1: Fig. S1. Transcription of G203R and C215Y alleles. (A) Schematic exon-intron structures of GNAO1. Black and white boxes mark the coding and noncoding parts of the exons respectively. The drawing of the exons is presented in scale. Digits inside the exons indicate their precise length in base pairs. Red arrows flag mutations in the $6^{\text {th }}$ exon. Primers used in RT-PCR are designated with black horizontal arrows. (B) Agarose gels with RT-PCR products obtained for different genotypes with the primers 1 and 2 as shown on panel (A). As expected, all resultant products migrate in gels as $160 \mathrm{bp}$ bands. (C) Sequences of RT-PCR products for GNAO1 mutants and the wt $(+/+)$ control. Codons, amino acids with their numbers are shown above the sequence of the wt. Black dashed vertical line demarcates the $5^{\text {th }}$ and $6^{\text {th }}$ exons. Red dashed vertical lines designate codons for the $203^{\text {rd }}$ and $215^{\text {th }}$ amino acids of Gao. Note that the peak height of the mutant nucleotide is nearly identical to that of wild-type in both mutants, speaking of near-equal expression of both alleles. Fig. S2. Normal striatum morphology in $\mathbf{C 2 1 5 Y}$ mutants. (A) Staining of brain sections with striatum identified with the Ctip2 marker (marks GABAergic medium-sized spiny neurons) from wt (+/+), C215Y/+, and C215Y/ C215Y E18.5 embryos. (B) DAPI staining of the same sections. Note the enlarged lateral ventricles (right to the striatum) in the $\mathrm{C} 215 \mathrm{Y}$ mutants. (C) Quantification of Ctip2-positive cells. (D) Quantification of the cell density by DAPI-stained cells in striatum. Data is presented as mean $\pm S D ; n=3$ animals. Scale bar: $0.5 \mathrm{~mm}$. Fig. S3. Normal hippocampus morphology in C215Y mutants. (A) Cresyl violet staining of coronal brain sections from wt (+/+), C215Y/+, and C215Y/C215Y E18.5 embryos does not reveal significant changes in the morphology of hippocampus. Scale bar: $100 \mu \mathrm{m}$. (B) Magnified photomicrographs of CA1 subfield of the hippocampus, marked with a rectangle in (A). Scale bar: $20 \mu \mathrm{m}$. (C) The graph summarizing CA1 neuronal counts as Data is presented as mean $\pm \mathrm{SD} ; \mathrm{n}=3$ animals. Fig. S4. Analysis of the upper layer cortical neurons and Cajal-Retzius cells in $\mathbf{C 2 1 5 Y}$ mutants. Staining of motor cortex brain sections from E18.5 wt (+/+), C215Y/+, and C215Y/C215Y mice for DAPI and Brn2 (layers II-V (A)), or DAPI and Reelin (marker of Cajal-Retzius cells, (B)). (C) Quantification of Brn2-positive cells. (D) Quantification of Reelin-positive cells. Data is presented as mean $\pm S D ; n=3-5$ animals; ${ }^{* *} p<0.01$, significance from

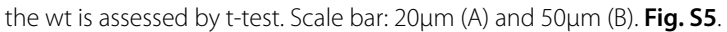
Normal levels of apoptosis in C215Y brain sections. The distribution of cleaved caspase-3 (CC3)-positive cell in the brain sections from E18.5 wt $(+/+), C 215 Y /+$, and C215Y/C215Y mouse embryos. (A) Representative immunohistochemistry pictures of cleaved caspase-3 (CC3)-positive cells (marked with arrows) in the cortical plate, scale bar $20 \mu \mathrm{m}$. The counting of caspase-3 positive cell in the cortical plate (B), the subventricular zone (C) and the ventricular zone (D). Data is presented as mean $\pm S D, n=3$; t-test did not reveal any statistically significant differences from wt. Fig. S6 G203R mutation affects brain morphology, neurons in deep and upper cortical layers as well as neural progenitor cells. (A) Hematoxylin and eosin staining of coronal brain sections from G203R/t, G203R/G203R and wt $(+/+)$ littermates at embryonic day 18.5 shows enlargement of lateral ventricles in G203R/+ and reduction in G203R/G203R mice. (B) Coronal sections through the motor cortex show differences in cortical thickness between wt and G203R/+ mice. (C) Staining of brain sections (at motor cortex) from E18.5 G203R/+, G203R/G203R and +/+ littermates for Tbr1 (layer VI), Ctip2 (weak in layer VI, strong in layer V), Brn2 (layer II/III), Reelin (marker of Cajal-Retzius cells), Tbr2 (marker of intermediate neuronal progenitor cells) and Nestin (marker of radial glial cells). Scale bars: $1 \mathrm{~mm}(A)$, $100 \mu m(B, C)$. Fig. S7. Additional data for the open field and pole tests. (A) Open field test: group mean of the time in the center of open field arena for the $+/+, C 215 Y /+$, and $C 215 Y / C 215 Y$ mice. (B) C215Y/+ mice remained more mobile than wt in the open field test despite the overall suppression of motility induced by risperidone treatment $(0.1 \mathrm{mg} / \mathrm{kg})$. Data is shown as distance moved by a mouse in the period of 30min of the experiment. (C) Pole test: means of time to a T-turn and time to descend in the pole test 
for the three genotypes. Data are presented as in Figure 5. Fig. S8. MoSeq quantification of the exploratory behavior under unchallenged conditions. The modified MoSeq algorithm was applied to monitor and analyze behavior of C215Y/+ and C215Y/C215Y female mice, alongside with their wt littermates, under non-challenged conditions in a square open field. The heatmaps demonstrate comparisons among the three genotypes for the syllable (behAdditional file 1: avioral pattern) frequency (number of times this syllable starts per minute of activity), mean length (the time the syllable lasts before changing to another syllable) and its overall proportion in percent over the entire analyzed time. Statistical significance was assessed by Dunn's multiple comparison test for each syllable and is shown as a number of compared group on top of the heatmap cell in case of a significant difference ( $p$ value $<0.05$ ), numbers are shown side by side in case of significant differences in 2 groups. Syllable description is provided below the heatmaps. Fig. S9. Detailed view of selected syllables representing majority of forward, sitting and rearing-related movements. The main characteristics of these syllables shown in Fig. S9 as a heatmap represented here as bar charts. Significance was assessed as in Fig. S7, ${ }^{*} p<0.05,{ }^{* *} p<0.01,{ }^{* * *} p<0.001$. Fig. S10. Networks analysis of MoSeq behavioral data. Transitions between behavioral syllables for wt (A), C215Y/+ (B), and C215Y/C215Y (C) animals. The syllables are shown as nodes and grouped by their gross appearance. The node size corresponds to the overall proportion of the syllable over the recording time (as shown on heatmaps in Fig. S8), nodes of syllables showing significant differences in at least one aspect (frequency, length or proportion,) are marked in red. Edge thickness corresponds to a proportion (in \%) of a given transition pair among all recorded transitions for the genotype, purple numbers are shown for edges with thickness $>0.2$. Edges with thickness $<0.01$ represent rare transitions and are thus not shown. Fig. S11. Absence of epileptic manifestations in $\mathbf{C 2 1 5 Y / + ~ m i c e . ~ S u r f a c e ~ E E G ~ r e c o r d i n g s ~ i n ~}$ control and mutant awake mice. (A) The head-fix epicranial EEG recording setup. The right image illustrates the localizations of the electrodes over the mouse brain. In red, the electrodes positioned above the somatosensory cortex regions. (B) Examples of $10 \mathrm{sec}$ windows of background EEG recorded in both control and mutant mice. (C) Illustrative examples of physiologic fast ripples (FRs) recorded over the somatosensory cortex in control and mutant mice as visible in the raw signals and in the signal filtered between 200-550Hz. (D, E) Pentylenetetrazole (PTZ)-induced mouse kindling reveals no difference between $\mathrm{C} 215 \mathrm{Y} /+$ and wt mice. Scheme of the experiment is shown in (D). In (E), seizure score quantification at three different injections of PTZ. Data are shown as mean $\pm S D, n=5(w t)$ and 7 $(C 215 Y /+)$ mice.

\section{Acknowledgements}

We thank Camilla Bellone for the help with and access to the setup for behavioral experiments, and Gonzalo Solis for critically reading the manuscript. The work was supported by the Swiss National Science Foundation Grant \#31003A_175658 and by the Russian Science Foundation Grant \#21-15-00138 (to contribute to the brain anatomy investigation of the mutant mice) to V.L.K. Figure 5D-F and Supplementary Fig. S7C were created with BioRender.com.

\section{Authors' contributions}

All authors read and approved the final manuscript.

\section{Declarations}

\section{Competing interests}

The authors declare that they have no Competing interests.

\section{Author details}

'A.N. Belozersky Research Institute of Physico-Chemical Biology, Moscow State University, 119992 Moscow, Russia. ${ }^{2}$ V.I. Kulakov National Medical Research Center of Obstetrics, Gynecology and Perinatology, Moscow 117997, Russia. ${ }^{3}$ Department of Cell Physiology and Metabolism, Faculty of Medicine, Translational Research Center in Oncohaematology, University of Geneva, 1211 Geneva, Switzerland. ${ }^{4}$ School of Biomedicine, Far Eastern Federal University, 690090 Vladivostok, Russia. ${ }^{5}$ Department of Basic Neuroscience, Faculty of Medicine, University of Geneva, 1211 Geneva, Switzerland. ${ }^{6}$ Transgenesis
Core Facility, Faculty of Medicine, University of Geneva, 1211 Geneva, Switzerland.

Received: 17 November 2021 Accepted: 8 January 2022

Published online: 28 January 2022

\section{References}

1. Schirinzi T, Garone G, Travaglini L, Vasco G, Galosi S, Rios L, Castiglioni C, Barassi C, Battaglia D, Gambardella ML et al (2019) Phenomenology and clinical course of movement disorder in GNAO1 variants: Results from an analytical review. Parkinsonism Relat Disord 61:19-25. https://doi.org/10. 1016/j.parkreldis.2018.11.019

2. Nakamura K, Kodera H, Akita T, Shiina M, Kato M, Hoshino H, Terashima H, Osaka H, Nakamura S, Tohyama J et al (2013) De Novo mutations in GNAO1, encoding a Galphao subunit of heterotrimeric $G$ proteins, cause epileptic encephalopathy. Am J Hum Genet 93:496-505. https://doi.org/ 10.1016/j.jhg.2013.07.014

3. Axeen E, Bell E, Robichaux Viehoever A, Schreiber JM, Sidiropoulos C, Goodkin HP (2021) Results of the first GNAO1-related neurodevelopmental disorders caregiver survey. Pediatr Neurol 121:28-32. https://doi.org/ 10.1016/j.pediatrneurol.2021.05.005

4. Kelly M, Park M, Mihalek I, Rochtus A, Gramm M, Pérez-Palma E, Axeen ET, Hung CY, Olson H, Swanson L et al (2019) Spectrum of neurodevelopmental disease associated with the GNAO1 guanosine triphosphatebinding region. Epilepsia 60:406-418. https://doi.org/10.1111/epi.14653

5. Saitsu H, Fukai R, Ben-Zeev B, Sakai Y, Mimaki M, Okamoto N, Suzuki Y, Monden Y, Saito H, Tziperman B et al (2016) Phenotypic spectrum of GNAO1 variants: epileptic encephalopathy to involuntary movements with severe developmental delay. Eur J Hum Genet 24:129-134. https:// doi.org/10.1038/ejhg.2015.92

6. Arya R, Spaeth C, Gilbert DL, Leach JL, Holland KD (2017) GNAO1-associated epileptic encephalopathy and movement disorders: c.607G $>$ A variant represents a probable mutation hotspot with a distinct phenotype. Epileptic Disord 19:67-75. https://doi.org/10.1684/epd.2017.0888

7. Schorling DC, Dietel T, Evers C, Hinderhofer K, Korinthenberg R, Ezzo D, Bönnemann CG, Kirschner J (2017) Expanding phenotype of De Novo mutations in GNAO1: four new cases and review of literature. Neuropediatrics 48:371-377. https://doi.org/10.1055/s-0037-1603977

8. Wirth T, Tranchant C, Drouot N, Keren B, Mignot C, Cif L, Lefaucheur R, Lion-Francois L, Meneret A, Gras D et al (2020) Increased diagnostic yield in complex dystonia through exome sequencing. Parkinsonism Relat Disord 74:50-56. https://doi.org/10.1016/j.parkreldis.2020.04.003

9. Carecchio M, Invernizzi F, Gonzàlez-Latapi P, Panteghini C, Zorzi G, Romito L, Leuzzi V, Galosi S, Reale C, Zibordi F et al (2019) Frequency and phenotypic spectrum of KMT2B dystonia in childhood: a single-center cohort study. Mov Disord 34:1516-1527. https://doi.org/10.1002/mds.27771

10. Benato A, Carecchio M, Burlina A, Paoloni F, Sartori S, Nosadini M, d'Avella D, Landi A, Antonini A (2019) Long-term effect of subthalamic and pallidal deep brain stimulation for status dystonicus in children with methylmalonic acidemia and GNAO1 mutation. J Neural Transm (Vienna) 126:739-757. https://doi.org/10.1007/s00702-019-02010-2

11. Solis GP, Kozhanova TV, Koval A, Zhilina SS, Mescheryakova TI, Abramov AA, Ishmuratov EV, Bolshakova ES, Osipova KV, Ayvazyan SO et al (2021) Pediatric encephalopathy: clinical, biochemical and cellular insights into the role of Gln52 of GNAO1 and GNAl1 for the dominant disease. Cells. https://doi.org/10.3390/cells10102749

12. Haeussler M (2020) CRISPR off-targets: a question of context. Cell Biol Toxicol 36:5-9. https://doi.org/10.1007/s10565-019-09497-1

13. Zhang X-H, Tee LY, Wang X-G, Huang Q-S, Yang S-H (2015) Off-target effects in CRISPR/Cas9-mediated genome engineering. Mol Ther Nucleic Acids 4:e264. https://doi.org/10.1038/mtna.2015.37

14. Truett GE, Heeger P, Mynatt RL, Truett AA, Walker JA, Warman ML (2000) Preparation of PCR-quality mouse genomic DNA with hot sodium hydroxide and tris (HotSHOT). Biotechniques 29(52):54. https://doi.org/ 10.2144/00291 bm09

15. Stringer C, Wang T, Michaelos M, Pachitariu M (2021) Cellpose: a generalist algorithm for cellular segmentation. Nat Methods 18:100-106. https:// doi.org/10.1038/s41592-020-01018-X 
16. Glangetas C, Espinosa P, Bellone C (2020) Deficit in motor skill consolidation-dependent synaptic plasticity at motor cortex to dorsolateral striatum synapses in a mouse model of Huntington's disease. eNeuro. https://doi.org/10.1523/eneuro.0297-19.2020

17. Southwell AL, Ko J, Patterson PH (2009) Intrabody gene therapy ameliorates motor, cognitive, and neuropathological symptoms in multiple mouse models of Huntington's disease. J Neurosci 29:13589-13602. https://doi.org/10.1523/jneurosci.4286-09.2009

18. Ogawa N, Hirose $Y$, Ohara S, Ono T, Watanabe Y (1985) A simple quantitative bradykinesia test in MPTP-treated mice. Res Commun Chem Pathol Pharmacol 50:435-441

19. Wiltschko AB, Tsukahara T, Zeine A, Anyoha R, Gillis WF, Markowitz JE, Peterson RE, Katon J, Johnson MJ, Datta SR (2020) Revealing the structure of pharmacobehavioral space through motion sequencing. Nat Neurosci 23:1433-1443. https://doi.org/10.1038/s41593-020-00706-3

20. Wiltschko Alexander B, Johnson Matthew J, lurilli G, Peterson Ralph E, Katon Jesse M, Pashkovski Stan L, Abraira Victoria E, Adams Ryan P, Datta Sandeep R (2015) Mapping sub-second structure in mouse behavior. Neuron 88:1121-1135. https://doi.org/10.1016/j.neuron.2015.11.031

21. Hadjas LC, Schartner MM, Cand J, Creed MC, Pascoli V, Lüscher C, Simmler LD (2020) Projection-specific deficits in synaptic transmission in adult Sapap3-knockout mice. Neuropsychopharmacology 45:2020-2029. https://doi.org/10.1038/s41386-020-0747-3

22. Sheybani L, Birot G, Contestabile A, Seeck M, Kiss JZ, Schaller K, Michel CM, Quairiaux C (2018) Electrophysiological evidence for the development of a self-sustained large-scale epileptic network in the kainate mouse model of temporal lobe epilepsy. J Neurosci 38:3776-3791. https://doi.org/10.1523/JNEUROSCI.2193-17.2018

23. Sheybani L, van Mierlo P, Birot G, Michel CM, Quairiaux C (2019) Largescale 3-5 Hz oscillation constrains the expression of neocortical fast ripples in a mouse model of mesial temporal lobe epilepsy. eNeuro. https:// doi.org/10.1523/eneuro.0494-18.2019

24. Lévesque M, Bortel A, Gotman J, Avoli M (2011) High-frequency (80-500 $\mathrm{Hz}$ ) oscillations and epileptogenesis in temporal lobe epilepsy. Neurobiol Dis 42:231-241. https://doi.org/10.1016/j.nbd.2011.01.007

25. Dhir A (2012) Pentylenetetrazol (PTZ) kindling model of epilepsy. Curr Protoc Neurosci Chapter 9(Unit9):37. https://doi.org/10.1002/04711 42301.ns0937s58

26. Shimada T, Yamagata K (2018) Pentylenetetrazole-induced kindling mouse model. J Vis Exp. https://doi.org/10.3791/56573

27. Jiang M, Gold MS, Boulay G, Spicher K, Peyton M, Brabet P, Srinivasan Y, Rudolph U, Ellison G, Birnbaumer L (1998) Multiple neurological abnormalities in mice deficient in the G protein Go. Proc Natl Acad Sci U S A 95:3269-3274

28. Cha HL, Choi JM, Oh HH, Bashyal N, Kim SS, Birnbaumer L, Suh-Kim H (2019) Deletion of the a subunit of the heterotrimeric Go protein impairs cerebellar cortical development in mice. Mol Brain 12:57. https://doi.org/ 10.1186/s13041-019-0477-9

29. Molyneaux BJ, Arlotta P, Menezes JR, Macklis JD (2007) Neuronal subtype specification in the cerebral cortex. Nat Rev Neurosci 8:427-437. https:// doi.org/10.1038/nrn2151

30. Bulfone A, Smiga SM, Shimamura K, Peterson A, Puelles L, Rubenstein $J$ (1995) T-brain-1: a homolog of Brachyury whose expression defines molecularly distinct domains within the cerebral cortex. Neuron 15:63-78. https://doi.org/10.1016/0896-6273(95)90065-9

31. Leone DP, Srinivasan K, Chen B, Alcamo E, McConnell SK (2008) The determination of projection neuron identity in the developing cerebral cortex.
Curr Opin Neurobiol 18:28-35. https://doi.org/10.1016/j.conb.2008.05. 006

32. Ananth AL, Robichaux-Viehoever A, Kim YM, Hanson-Kahn A, Cox R, Enns GM, Strober J, Willing M, Schlaggar BL, Wu YW et al (2016) Clinical course of six children with GNAO1 mutations causing a severe and distinctive movement disorder. Pediatr Neurol 59:81-84. https://doi.org/10.1016/j. pediatrneurol.2016.02.018

33. Larrivee $C L$, Feng H, Quinn JA, Shaw VS, Leipprandt JR, Demireva EY, Xie H, Neubig RR (2020) Mice with GNAO1 R209H movement disorder variant display hyperlocomotion alleviated by risperidone. J Pharmacol Exp Ther 373:24-33. https://doi.org/10.1124/jpet.119.262733

34. Yang $X$, Niu X, Yang Y, Cheng M, Zhang J, Chen J, Yang Z, Zhang Y (2021) Phenotypes of GNAO1 variants in a Chinese cohort. Front Neurol 12:662162. https://doi.org/10.3389/fneur.2021.662162

35. Larasati Y, Savitsky M, Koval A, Solis G, Katanaev V (2021) Restoration of the GTPase activity of Gao mutants by Zn2+ in GNAO1 encephalopathy models. Res Sq. https://doi.org/10.21203/rs.3.rs-900405/v1

36. Wang D, Dao M, Muntean BS, Giles AC, Martemyanov KA, Grill B (2021) Genetic modeling of GNAO1 disorder delineates mechanisms of Gao dysfunction. Hum Mol Genet. https://doi.org/10.1093/hmg/ddab235

37. Di Rocco M, Galosi S, Lanza E, Tosato F, Caprini D, Folli V, Friedman J, Bocchinfuso G, Martire A, Di Schiavi E et al (2021) Caenorhabditis elegans provides an efficient drug screening platform for GNAO1-related disorders and highlights the potential role of caffeine in controlling dyskinesia. Hum Mol Genet. https://doi.org/10.1093/hmg/ddab296

38. Muntean BS, Masuho I, Dao M, Sutton LP, Zucca S, Iwamoto H, Patil DN, Wang D, Birnbaumer L, Blakely RD et al (2021) Gao is a major determinant of CAMP signaling in the pathophysiology of movement disorders. Cell Rep 34:108718. https://doi.org/10.1016/j.celrep.2021.108718

39. Kehrl JM, Sahaya K, Dalton HM, Charbeneau RA, Kohut KT, Gilbert K, Pelz MC, Parent J, Neubig RR (2014) Gain-of-function mutation in Gnao1: a murine model of epileptiform encephalopathy (EIEE17)? Mamm Genome 25:202-210. https://doi.org/10.1007/s00335-014-9509-z

40. Danti FR, Galosi S, Romani M, Montomoli M, Carss KJ, Raymond FL, Parrini E, Bianchini C, MCShane T, Dale RC et al (2017) GNAO1 encephalopathy: broadening the phenotype and evaluating treatment and outcome. Neurol Genet 3:e143. https://doi.org/10.1212/nxg.0000000000000143

41. Marcé-Grau A, Dalton J, López-Pisón J, García-Jiménez MC, MongeGalindo L, Cuenca-León E, Giraldo J, Macaya A (2016) GNAO1 encephalopathy: further delineation of a severe neurodevelopmental syndrome affecting females. Orphanet J Rare Dis 11:38. https://doi.org/10.1186/ s13023-016-0416-0

42. Koy A, Cirak S, Gonzalez V, Becker K, Roujeau T, Milesi C, Baleine J, Cambonie G, Boularan A, Greco F et al (2018) Deep brain stimulation is effective in pediatric patients with GNAO1 associated severe hyperkinesia. J Neurol Sci 391:31-39. https://doi.org/10.1016/j.jns.2018.05.018

\section{Publisher's Note}

Springer Nature remains neutral with regard to jurisdictional claims in published maps and institutional affiliations.

Ready to submit your research? Choose BMC and benefit from:

- fast, convenient online submission

- thorough peer review by experienced researchers in your field

- rapid publication on acceptance

- support for research data, including large and complex data types

- gold Open Access which fosters wider collaboration and increased citations

- maximum visibility for your research: over $100 \mathrm{M}$ website views per year

At $\mathrm{BMC}$, research is always in progress.

Learn more biomedcentral.com/submissions 